\title{
Лексические и стилистические средства создания современной персидской рекламы
}

\author{
Гулиев Анар Рагим Оглы \\ Кафедра языков и литератур Ближнего и Среднего Востока, Киевский национальный университет имени Тараса Шевченко \\ (Министерство образования и науки Украины) 01601, г. Киев, бульвар Шевченко 14 \\ Corresponding author. E-mail: anar@espresso.az
}

Paper received 16.01.19; Accepted for publication 22.01.19.

\section{https://doi.org/10.31174/SEND-Ph2019-189VII55-05}

\begin{abstract}
Аннотация. С точки зрения языкознания, одним из научных интересов представляются лексические и стилистические средства, использованные при создании современной персидской рекламы. Персидский рекламный текст, как и другие, имеет три главных элемента: заголовок, основной текст и рекламный лозунг - слоган, выражающий его основную мысль, выполняющий воздействующую и информирующую функции. Основная цель смысла-общения в рекламе, особенно, в рекламном слогане, является призыв к действию. Действенность слогана позволяет выполнить его функцию-принуждение к деятельности. Именно этот призыв и принуждение претворяются в жизнь с помощью лексических и стилистических средств языка. В этой статье с этой позиции и исследуются лексические и стилистические средства, использованные при создании современной персидской рекламы.
\end{abstract}

Ключевые слова: лексический, стилистический, средство, современный, реклама, персидский

Введение. Как известно, язык является средством общения в широком смысле этого слова. В зависимости от места, времени, формы и характера общения, используются те или иные возможности широкого языкового спектра.

С этой точки зрения лексические и стилистические средства имеют свое собственное место среди этих возможностей. Они играют особую значимость в рекламном творчестве. Потому что реклама является особой формой общения [1, с. 611]. Она носит, в основном, торгово-коммерческую цель. То есть, она акцентирует внимание на заслугах (преимуществах) продаваемого товара или предоставляемой услуги с целью создания спроса и дальнейшего его удовлетворения. В современном мире из-за возросшего значения материального, из-за важной роли купли-продажи в жизни общества, а также в связи с желанием отдельных индивидуумов достичь больших успехов при продаже товаров и услуг, значение реклама многократно возросло и продолжает расти. С этой точки зрения ведение научные исследования в области рекламы, особенно, рекламного слогана, в сфере ее лексических и стилистических средств имеет актуальней характер.

Объектом данного исследования является экспрессивная лексика, современного персидского рекламного слогана. Предметом нашего исследования выступают лексические и стилистические средства, которые применяются для создания современного персидского рекламного слогана. А цель работы выявить лексические и стилистические средства, которые применяются для создания языковой экспрессивности в современных персидских рекламных слоганах.

Для изучения были отобраны 100 персидских слоганов (приложение 1) и исследования проводились на их основании. В процессе работы были использованы методы описания, классификации, сравнения и сравнительного анализа.

Говоря о стиле, в первую очередь, на ум приходит литературно-художественный стиль. У каждого автора его стиль есть набор проявляющих себя параметров, их единое целое [3, с. 23]. Как в устном народном творчестве, так и в письменной литературе, в центре внимания всегда были правила высказываний, смысловая нагрузка, форма выражения, отображаемая мысль, мудрость изречений [2, с. 39]. Дело в том, что на Ближнем и Среднем Востоке в средние века персидский язык являлся одним из трех основных используемых языков (арабский, персидский и турецкий) и многие шедевры мировой литературы созданы именно на этом языке. Если учесть, что в указанный исторический период большинство художественных и поэтических произведений создано на персидском, то можно говорить о достаточном использовании лексических и стилистических свойств этого богатейшего языка. Известные художественно-литературные лексические и стилистические изыски персидского языка, выявленные на протяжении веков сыграли особую роль в развитии рекламного производства после появления рекламной промышленности. Естественно, что к этому богатству были добавлены и коммерческие цели, и в результате созданы богатые лексические и стилистические средства современной персидской рекламы и рекламного слогана.

Слоган обладает высокой экспрессивностью, имеет призывный характер. Экспрессивность-это весь комплекс стилистических, семантических речевых признаков, которые позволяют выражать субъективную позицию говорящего в отношении предмета или адресата. Слово имеет латинский корень “expressio", что обозначает выражение. Экспрессивность-одно из речевых свойств, что связано непосредственно с эмоциональной оценкой сообщаемой информации, субъективно воспринимаемой и бессознательно выражаемой говорящим [4]. Экспрессивность рекламного слогана достигается за счёт использования в нём разнообразных лексических и стилистических средств языка, их удачного подбора и сочетания. Правильный подбор лексики в рекламном слогане обеспечивает его экспрессивность и, в конечном счёте, успешность и популярность. Лексику, употребление которой в рекламном тексте играет важную роль, можем разделить на следующие группы:

1. Абстрактная, конкретная или специфическая 
лексика: например, آب كوثر نوشابه بهتر Абе коусер луч-

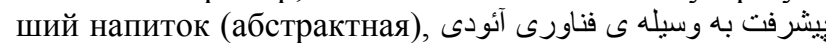
- Ауди развитие с помощью технологии (конкретная), - در دهانتا آب مى شود نه در دستتان ام اند ام вает во рту, а не в руках (специфическая);

2. Иностранная и исконная лексика: например, - Апл думай по другому (иностранная), - Еттелаат старинная газета Ирана (исконная);

3. Эмоционально-окрашенная и нейтральная лексика: например, اير انسل بزركترين اوبِراتورو بيشرو در كسب - Иشترى - Ирансел самый большой оператор и передовик по привлечению клиента (эмоционально-окрашенная), - Бانكى پِنداز استقبال رفاه - Банк Пасандаз будущее благополучия (нейтральная);

4. Семантически-положительная или семантически-отрицательная лексика: например, تبليغات به آينده - Таبيت خوش آمديد щее пропаганды (семантически-положительная), مطئن جيبس نميتو انيد فقط يكى بخوريد - Чипс наверно не сможете есть только один (семантически-отрицательная);

5. С прямым или переносным значением слов: например, بيمانه تمام فن ها يه جا - Пеймане все предметы в

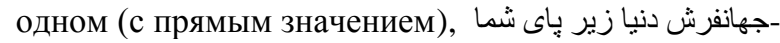
Джаханфарш мир под Вашими ногами (с переносным значением);

6. Разговорная и книжная лексика: например, هجاب Хеджаб честь и достоинство женщины (разговорная), سيركشت بهترين سير جهان - Сейре гешт наилучший тур мира (книжная);

7. Низкочастотные слова и часто употребляемые. например, قلمجى 47 سال به رفاه شما - Галемчи 47 лет для Вашего благополучия (низкочастотное слово), برنامه خانو اده از خانو اده خودنونه - Барнамейе Ханаваде из Ваших семей (часто употребляемое слово).

Общие черта собранных нами 100 рекламных слоганов по использованию частей речи следующие:

1. Преимущественное использование части речиглагола для выполнения главной задачи слогана побуждать к действию, причем в большей мере императива, также фразовые и глаголы чувственного восприятия;

2. Широкое использование личных и притяжательных местоимений для адресности рекламы;

3. Широкий спектр эмоционально-емких прилагательных и наречий.

Стилистические средства выразительности языка придают слогану красочность, образность и запоминаемость, поскольку представляют в яркой форме основную идею рекламной компании. А полисемия является мощным средством повышения экспрессивности в рекламном слогане и базой для образования и применения в них многочисленных тропов. Стилистическим средством выражения экспрессии в слоганах служит специфический подбор слов. Например, низкочастотные слова привносят в текст рекламного слогана необычность, и способствует его высокой узнаваемости. А многозначные слова придают слогану игривость. Неологизмы повышают оригинальность, эмоциональность и привлекают внимание потенциального покупателя. Кроме того, разнообразные художественные средства выразительности-тропы придают рекламному тексту образность, создают особый эмоциональный фон, новый стилистический оттенок. В исследуемых нами слоганах имеются и фразеологизмы, метафора и эпитеты. Причем наибольшей экспрессивностью обладает в слоганах метафора. А эпитеты подчеркивают специфику и уникальные качества предмета рекламы. Следует отметить, что в некоторых слоганах игра слов, то есть каламбур способствует повышению эмоциональности слогана. Гипербола преувеличивает качеств и способности продукта рекламы. Кроме вышеизложенного, в исследуемых нами слоганах есть и менее используемые стилистические художественные средства выражения экспрессивности, как сравнение, контраст, олицетворение, метонимия, ирония, синекдоха, иллюзия. Сравнение используется для демонстрации исключительности и придания повышенной эмоциональности предмету рекламы, контраст выделяет предмету рекламы, олицетворение эмоционально выражает действия, метонимия способствует образной связи между объектами, ирония усиливает эмоциональное отношение, синекдоха скрыто рекламирует товара, иллюзия ассоциирует адресата с определенными эмоциями.

Вывод. Изучив 100 примеров персидского рекламного слогана, приходим к следующим выводам:

1. Язык исследуемых нами слоганов является экспрессивным;

2. Поскольку природа рекламного слогана многоаспектна, его эмоциональность зависит от удачного подбора и сочетания лексических и стилистических средств языка;

3. На лексическом уровне для выражения экспрессивности в персидском рекламном слогане преимущественно используется следующая лексика:

- по заряду-положительная лексика;

- по смысловому назначению-конкретная и абстрактная лексика;

- по эмоциональной окраске-эмоциональноокрашенная лексика;

- по происхождению-исконная лексика;

- по стилю-книжная лексика;

- по назначению-многозначная лексика.

4. На стилистическом уровне для выражения экспрессивности в персидском рекламном слогане преимущественно используются следующие средства: неологизмы, фразеологизмы, метафора, эпитеты, каламбур и др.

5. Наиболее часто используемыми частями речи для представления основной идеи рекламы и передачи экспрессии в современном персидском рекламном слогане являются глаголы, эмоциональнонаполненные прилагательные, наречия, личные и притяжательныеместоимения.

6. 80 \% всех случаев экспрессивность слоганов достигадась за счет использования экспрессивной лексики, то есть лексическими средствами. А в $90 \%$ исследуемых нами слоганов использовались стилистические средства выразительности для передачи экспрессии в рекламном слогане. 


\section{ЛИТЕРАТУРА}

1. Большая Советская Энциклопедия. Третье издание, т. 21. Москва: Советская энциклопедия, 1975, 639 с.

2. İbrahimov S. M. Azərbaycan ədəbiyyatşünaslığının tarixi, metodologiyası və problemləri. Bak1: Bak1 Dövlət

Universiteti. 2012, $183 \mathrm{~s}$.

3. در آمدي بر سبك شناسي سـاختاري، محمدتقي غياني، انتشـار ات علمي، تهر ان، 1375، 179 صفحه.

4. http://psihomed.com/ekspressivnost/ проверено 10.01.2019

1. Large Soviet Encyclopedia. The third publication, cover 21. Moscow: Soviet Encyclopedia, 1975. 639 p.

2. Ibrahimov S.M. History, methodology and problems of Azerbaijan literary criticism. Baku: Baku State University. 2012.

\section{REFERENCES}

$183 \mathrm{p}$.

3. Introduction to the style. Muhammadtagı Qiyasi. Tehran: publishing house "Elmi". 1375. $179 \mathrm{p}$.

4. http://psihomed.com/ekspressivnost/ проверено 10.01.2019

ПРИЛОЖЕНИЕ 1

\begin{tabular}{|c|c|c|}
\hline \multicolumn{3}{|c|}{ Бренд и его слоган } \\
\hline На русском & Транскрипция & На персидском \\
\hline Абе коусер лучший напиток & Abe kousər nushabeye behtər & 1. آب كوثر نوشابه بهتر \\
\hline Авис больше стараемся & Avis bishtər sey mikonim & 2. آويس بيشتر تلاش مى كنيم \\
\hline $\begin{array}{l}\text { Ауди развитие с помощью техноло- } \\
\text { гии }\end{array}$ & Audi pishrəft be vəsileye fənnavəri & 3. أئودى بيشرفت به وسيله ى فناورى \\
\hline Ауди Формула S спорт стиль страсть & Audi Formula S vərzesh səbk ve ehteras & 4. أؤدى فرمو لا س ورزش سبك و احتر اس \\
\hline $\begin{array}{l}\text { Адбид нескольким нажатием свой } \\
\text { бизнес делай международным }\end{array}$ & $\begin{array}{l}\text { Adbid ba chənd klik kəsb o kare xodra cəhani } \\
\text { kon }\end{array}$ & كنيد آدبيد با جند كليى كسب و كار خود را جهانى \\
\hline Апл думай по другому & Opl motəfavet beəndish & 6. إِل متفاوت بينديش \\
\hline Естекбал другая постель & Estegbal bəstəre digər əst & 7. استقبال بستر ديكر است \\
\hline $\begin{array}{l}\text { Еститфарм как хороший сосед рядом } \\
\text { с Вами }\end{array}$ & $\begin{array}{l}\text { Estitfarm mesle yek həmsayeye xub dər kenare } \\
\text { shomast }\end{array}$ & شما استيت فارم مثل يك همسايه ى خوب در كنار \\
\hline $\begin{array}{l}\text { Еттелаат с } 93 \text { летним постоянным } \\
\text { изданием }\end{array}$ & Ettelaat ba 93 sal enteshare mostəmər & 9. اطلاعات با 93 سال انتشار مستمر \\
\hline Еттелаат старинная газета Ирана & Ettelaat qədimterin ruznameye İran & 10. اطلاعات قديمترين روزنامه ايران \\
\hline Электростиль качество и нежность & Elektrostil keyfiyyet ve zerafet & 11. الكتروستيل كيفيت و ظر افت \\
\hline $\begin{array}{l}\text { М и М размораживает во рту, а не в } \\
\text { руках }\end{array}$ & $\begin{array}{l}\mathrm{M} \text { end } \mathrm{M} \text { dər dəhanetan ab mishəvəd ne dər } \\
\text { dəstetan }\end{array}$ & 12. ام اند ام در دهانتا آب مى شود نه در دستتان \\
\hline $\begin{array}{l}\text { Иранское общество дарения органов } \\
\text { дарение органа спасение жизни }\end{array}$ & $\begin{array}{l}\text { Oncoməne ehdaye ozve iraniyan ehdaye ozv } \\
\text { ehdaye zendegi }\end{array}$ & |احداى زندكى احداى عضو اير انييان احداى عضو \\
\hline $\begin{array}{l}\text { Иранхебер все информация, подле- } \\
\text { жавшая к печати }\end{array}$ & İranxəbər həmeye əxbare gabele chap & 14. ايران خبر همه اخبار قابل جابٍ \\
\hline $\begin{array}{l}\text { мый большой оператор и } \\
\text { по привлечению клиента }\end{array}$ & $\begin{array}{l}\text { orgterin operat } \\
\text { teri }\end{array}$ & كسب مشترى اير بزركترين اوير اتورو يِيشرو در \\
\hline Иранфильм друг наших семей & İranfilm duste xanevadeyemun & 16. اير انفيلم دوست خانو اده مون \\
\hline Банк Айенде светлое будущее & Banke Ayənde ayəndeye roushen & 17. با نك آينده آينده روشن \\
\hline $\begin{array}{l}\text { Банк Ансар символ сервиса и дове- } \\
\text { рия }\end{array}$ & Banke Onsar nəmade xedmət ve etebar & 18. بانك انصسار نماد خدمت و اعتبار \\
\hline $\begin{array}{l}\text { Банк Пасагард банк третьего милле- } \\
\text { ниума }\end{array}$ & Banke Pasaqard banl & 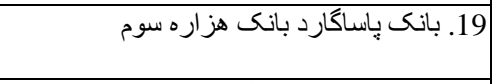 \\
\hline $\begin{array}{l}\text { Банк Пасандаз будущее благополу- } \\
\text { чия }\end{array}$ & səndaz & 20. بانك يֶنداز استقبال رفاه \\
\hline $\begin{array}{l}\text { Банк Маскан нуждайтесь в жилье? } \\
\text { Пожалуйста! }\end{array}$ & $\begin{array}{l}\text { Banke Məskən niyaz be məskən darid? } \\
\text { Befərmaid! }\end{array}$ & 21. بانك مسكن نياز به مسكن داريد؟ بفر مائيد! \\
\hline $\begin{array}{l}\text { Бартар черты нашей способности } \\
\text { Ваши соображения }\end{array}$ & $\begin{array}{l}\text { Bərtər məhdudeye təvane ma təsəvvorate } \\
\text { shomast }\end{array}$ & وده توان ما تصور ات شما ست \\
\hline це из Ваших семей & ye Xanevade əz xanevadeye xodet & 23. برنامه خانو اده از خانو اده خودتونها \\
\hline БМВ наконец одна а & BMW nehayetən yek xodro & 24. بمو نهايتا يك خودرو \\
\hline Бехруз, мой друг, здравствуй & Behruz, duste mən, səlam & 25. بهروز دوست من سلام \\
\hline Бехсазан создатели высшего & $\mathrm{n}$ behtorin s & 26. بهساز ان بهترساز انه \\
\hline возмездия & Bimey & ا 27. بيمه دى با شما براى جبران \\
\hline ментом & ye əknun zendegi kon & 28. يُشى بر اي اكنون زندكى كن \\
\hline Полибас совершенство мытья & amole sho & 29. يليباس تكامل شست و شو \\
\hline Пеймане все предметы в одном & Peymane təmame fənnha ye ca & 30. يبمانه تمام فن ها يه جا \\
\hline $\begin{array}{l}\text { Тармар спокойные ночи плодотвор- } \\
\text { ные рабочие дни }\end{array}$ & $\begin{array}{l}\text { Tarmar shəbhaye aram ruzhaye məhsuldare } \\
\text { kar }\end{array}$ & 31. نارمارشبهاى آر ام روز هاى محصولدار كار \\
\hline пяй по своей мечте & d edare kon & 32. تايوتا با آرزوى خود اداره كن \\
\hline $\begin{array}{l}\text { Табликат добро пожаловали в буду- } \\
\text { щее пропаганды }\end{array}$ & Təbligat be ayəndeye təbligat xosh amədid & 33. تبليغات به آينده تبليغت خوش آمديد \\
\hline $\begin{array}{l}\text { Теско даже одна маленькая частица } \\
\text { помогает }\end{array}$ & $\begin{array}{l}\text { Tesko hətta yek zərreye kuchek komək } \\
\text { mikonəd }\end{array}$ & 34. تسكوحتى يك ذره كوجى هم كمى مى كند \\
\hline Цитроен будущее разума & Chitroen estegbale təfəkkor & 35. جيتروين استقبال تفكر \\
\hline $\begin{array}{l}\text { Чипс наверно не сможете есть только } \\
\text { один }\end{array}$ & $\begin{array}{l}\text { Chips motmeinən nemitevanid fəgət yeki } \\
\text { bexorid }\end{array}$ & مطهئنأ نميتو انيد فقط يكى بخوريد \\
\hline
\end{tabular}




\begin{tabular}{|c|c|c|}
\hline Джелус лучшая разница & Celus təfavote behtər & 37. جلوس تفاوت بهتر \\
\hline $\begin{array}{l}\text { Дженерал электрик воображение на } \\
\text { работе }\end{array}$ & Ceneral elektrik təxəyyol dər kar & 38. جنر ال الكتريك تخيل در كار \\
\hline $\begin{array}{l}\text { Джаханфарш мир под Вашими нога- } \\
\text { ми }\end{array}$ & Cəhanfərsh donya zire paye shoma & | 39. جهانفرش دنبازير ياى شما \\
\hline $\begin{array}{l}\text { Джип Черике приключения привыч- } \\
\text { ки }\end{array}$ & Cip cheruke macəraha adəte & |40. جيّ جروكه ماجر اها عادته \\
\hline $\begin{array}{l}\text { Хейли себз для двенадцатиклассни- } \\
\text { ков }\end{array}$ & Xeyli səbz bəraye dəvazdehominha & 41 4يلى سبز براى دوازدهمين ها \\
\hline $\begin{array}{l}\text { Дарис улыбайтесь с каждой покуп- } \\
\text { кой }\end{array}$ & Daris ba hər xərid ləbxənd bezenid & 42. داريس با هر خريد لبخند بزنيد \\
\hline Даво качество и доступ наша честь & Davo keyfiyyət və dəstrəsi leyagete mast & 43. داوو كيفيت و دسترسى لياقت ما است \\
\hline Хайат вода органической жизни & Həyat abe orqanike həyat & 44. حيات آب اركانبك حيات \\
\hline $\begin{array}{l}\text { Данькин донатс Америка управляет- } \\
\text { ся Данькином }\end{array}$ & $\begin{array}{l}\text { Dankin donats Amrika ba dankin edare } \\
\text { mishəvəd }\end{array}$ & شو 45. دانكين دوناتس امريكا با دانكين اداره مى \\
\hline $\begin{array}{l}\text { Немайе таджхиз лучшие бренды с } \\
\text { наилучшими гарантиями }\end{array}$ & $\begin{array}{l}\text { Nemaye təchiz behtərin brendha ba } \\
\text { motəbərtərin qarantiha }\end{array}$ & 46 انتي دماى تجهيز بهترين برند ها با معتبرترين \\
\hline $\begin{array}{l}\text { Жилет наилучшая бритва для муж- } \\
\text { чин }\end{array}$ & Jilet behtərin tig bəraye mərdan & 47. زيلت بهترين تيغ براى مردان \\
\hline Рах ахане Иран ось развития & Rah ahəne İran mehvəre tousie & إه 48 راه آهن ايران محور توسعه \\
\hline Ройтел лучший цифровой оператор & Roytel operatore digitale behtər & 49. رويتل إير اتورديكينال بهتر \\
\hline Зам-зам вода райская & Zem-zem abe cənnoti & ا \\
\hline $\begin{array}{l}\text { Зендегиуе салем курение родителей } \\
\text { вредит и детям }\end{array}$ & $\begin{array}{l}\text { Zendegiye salem əz keşidəne siqare valideyn } \\
\text { bəchcheha həm asib mibinənd }\end{array}$ & هم 51. زندكى سالم از كثيدن سيخارو اليدين بجه ها \\
\hline Сана единство искусства и питания & Sana vəhdəte honər o təgziyye & 52. سانا وحدت هنر و تغذيه \\
\hline Сарауе Иран по & Səraye İran xərid ba ma & 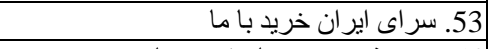 \\
\hline $\begin{array}{l}\text { Сарпуш самый распространенный } \\
\text { сайт }\end{array}$ & Sərpush xəbəri cameetərin sayt & |54. سريوش خبرى جامعترين سايت \\
\hline Сираб жизнь в каждой капли & Sirab dər hər ğetre & أ55. سير اب دد هر قطره اش حيات هست \\
\hline Семнантур откройте мир с нами & Semnantur donya ra ba ma kəshf konid & 56. سمنانتور دنيا را با ما كثف كنيد \\
\hline Сейре гешт наилучший тур мира & Seyre gəşt behtərin seyre donya & 57. سبركثت بهترين سير جهان \\
\hline Шабакейе 5 вместе с Вами & Shəbekeye 5 həmrah ba s & ا 58 شبكه 5 همر اه با شما \\
\hline Собхе шома с Вами & Sobhe shoma ba shoma & ا 59. صبح شما با شما \\
\hline Шабакейе 1 канал каждого иранца & Shəbəkeye 1 shəbəkeye hər irani & 60 6بكه 1 -شبكه هر ايرانى \\
\hline Шахре фарш войдите в новый мир & Shəhre fərsh vared donyayi cədid & 61. شهر فرش وارد دنياى جديد شويد \\
\hline Шевролит один год удобного сна & Shevrolit yek sal xabe rahət & 62. شوروليت يك سال خو اب راحت \\
\hline Фарше Машхад ш & Fərshe Məshhəd shahkare Məshhəd & 63. فرش مشهـ شاهكار مشهر \\
\hline $\begin{array}{l}\text { Флат пришло время двигаться доль- } \\
\text { ше }\end{array}$ & Flat zəmane hərəkəte durtər rəsid & 64. فلات زمان حركت دورتر رسيد \\
\hline ФМ 90 слушайте Иран & FM $90 \dot{\mathrm{I}}$ & 65. ف م 90 ايران را بشنويد \\
\hline Коран книга праведных & Koran ketabist bəraye pəhrizkaran & 66. قران كتابى است براى بـهريز كار ان \\
\hline $\begin{array}{l}\text { Галемчи } 47 \text { лет для Вашего благопо- } \\
\text { лучия }\end{array}$ & Qələmchi 47 sal be refahe shoma & 67. قلمجى 47 سال به رفاه شما \\
\hline Кадж группа передового обучения & Kac qoruhe al & 68. كاج كروه آموزشى يبشرو \\
\hline $\begin{array}{l}\text { Карйаби принцип найти работы, а не } \\
\text { опыт }\end{array}$ & Karyabi əsle karyaft est nə dəryaft & 69. كاريابى اصل كاريافت است نه دريافت \\
\hline Касни молодой секрет нашей кожи & Kasni raze cəvane pust mast & إن 70. كاسنى راز جوان يوست ما \\
\hline Кока кола пышность наслаждения & Koka kola ehteshame lezzet & ا 71 . كوكا كو لا احتشام لذت \\
\hline т отдыхай и ешь кит кат & Kit kat esterahet kon kit kat bexor & 72. كيت كات استر احت كن كيت كات بخور \\
\hline Голра & Qolreng bədəne shadab & 73. كلرنح بدن شـاداب \\
\hline Голдфайер с тройной силой & Qoldfayer be godrəte se bərabər & ا 74. كو لدفايربه قدرت سه بر ابر \\
\hline $\begin{array}{l}\text { Голфайер чистота, здоровье, без- } \\
\text { опасность, эффективность }\end{array}$ & Qoldfayer pak salem əmin moesser & 75. كو لدفايرباك سالم امين مؤثر \\
\hline $\begin{array}{l}\text { Гилантаблик первый сайт объявления } \\
\text { и рекламы }\end{array}$ & Gilantebliğ əvvəlin sayt agehi təbligat & 7. كيلان تبليغ اولين سايت آكهى تبليغات \\
\hline $\begin{array}{l}\text { Гилантаблик электронный символ и } \\
\text { доверие в области рекламы с центра }\end{array}$ & $\begin{array}{l}\text { Gilantəbliğ nəmad o etemade elektroniki dər } \\
\text { houzeye təbliğat əz mərkəz }\end{array}$ & 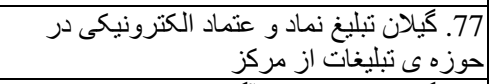 \\
\hline $\begin{array}{l}\text { Гилантаблик с малым объявлением } \\
\text { свой товар и сервис предъявите сот- } \\
\text { ни тысячи людям в день }\end{array}$ & $\begin{array}{l}\text { Gilantəbliğ ba yek agəhiye kuçek kala və } \\
\text { xedəmate xod ra be sədha hezar nəfər dər ruz } \\
\text { moərefi konid }\end{array}$ & 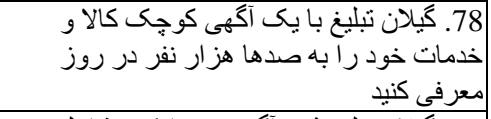 \\
\hline \begin{tabular}{|l|} 
Гилантаблик регистрация объявление \\
в банке лучших профессий \\
\end{tabular} & $\begin{array}{l}\text { Gilantəbliğ səbte agəhi dər banke məshağele } \\
\text { bərtər }\end{array}$ & 79. كيلان تبليغ ثبت آكهى در بانك مشاغل برتز \\
\hline Лотус особенная разница & Lotus təfavote məxsus & التوس تفاوت مخصوص \\
\hline $\begin{array}{l}\text { Лореал поскольку Вы достойны на } \\
\text { него }\end{array}$ & Loreal chon layegəsh həstid & |81. لورئال جون لايقش هستيد \\
\hline Лиза Мари новая кристальность & Liza Muri kristaliye nou & 82. ليزا مورى كريستالى نو \\
\hline $\begin{array}{l}\text { Мастеркарт возможность оплаты } \\
\text { везде и всегда }\end{array}$ & $\begin{array}{l}\text { Masterkart emkane pərdaxt bəraye hər ca və } \\
\text { hər zəman }\end{array}$ & 83. ماستركارت امكان يرداخ \\
\hline
\end{tabular}




\begin{tabular}{|c|c|c|}
\hline Марва достойна каждой мусульманке & Mərva layege hər zəne mosəlman & ا 84. مروا لايق هرزن مسلمان \\
\hline Макдональдс влюблен в него & Makdonalts asheğeməsh & ا \\
\hline Магзе бартар Ваш мозг для Вас & Məğze bərtər məğze shoma bəraye shoma & ا 86. مغز برترمغز شما به كمك شما \\
\hline Махде фарш секреты ковер & Məhde fərsh razeqane fərsh & 87. مهد فرش رازكان فرش \\
\hline Молфикс первый выбор мам & Molfiks entexabe evvele mamana & ا 88. مولفيكس انتخاب اول مامانا \\
\hline $\begin{array}{l}\text { Молфикс очень привлекательное } \\
\text { счастье }\end{array}$ & Molfiks xoshbəxtiye xeyli cazebtər & 89. مو لفيكس خوشبختى خيلى جاذبتر \\
\hline $\begin{array}{l}\text { Молфикс счастье завтра ребенок } \\
\text { завтра }\end{array}$ & Molfiks xoshbəxtiye fərda bəchcheye fərda & |90. مولفيكس خوشبختى فردا بجه فردا \\
\hline Монди с Монди будь в покое & Mondi ba mondi rahət kon & ا 91. موندى با موندى راحت كن \\
\hline $\begin{array}{l}\text { Митсубиши беспредельные возмож- } \\
\text { ности }\end{array}$ & Mitsubishi emkanate bihəd & |92. ميتسو بيشى امكانات بى حد \\
\hline Найки только выполняй & Nayki fəğət əncaməsh bedeh & إن 93. نايكى فقط انجامش بده \\
\hline НХ100 создай свой мир & NX100 donyaye xodət ra ehdas kon & 94. ن خ خ 100 دنباى خودت را احداث كن \\
\hline Насим канал улыбки и радости & Nəsim shəbəkeye neshat o shadi & 95. نسيم شبكه نشاط وشادى \\
\hline $\begin{array}{l}\text { Хеджаб честь и достоинство женщи- } \\
\text { ны }\end{array}$ & Hecab ezzət o shərəfe zəne & 96. هجاب عزت و شرف زنه \\
\hline $\begin{array}{l}\text { Веризон теперь слышишь меня? } \\
\text { Хорошо }\end{array}$ & Verizon hala sedaye mera mishenəvi? Xube & 97. وريزون حالا صدامو مى شنوى؟ خوبه \\
\hline Вестел предложение экономичности & Vestel pishnəhade sərfecuyi & 98. وستل بيشنهاد صرفه جويى \\
\hline Витиз завтрак героев & Vitiz sobhaneye ğəhrəmanan & 99. ويتنزصبحانه ى قهرمان ها \\
\hline $\begin{array}{l}\text { Йаташ если уснуть проблема, то } \\
\text { помощь в Йаташе }\end{array}$ & Yatash əgər moshkel xab əst chare Yatash əst & |100. ياتاش اكر مشكل خو اب است جاره ياتاش \\
\hline
\end{tabular}

\section{Lexical and stylistic means of the creation Of the advertisement of modern Persian}

Anar R. Guliyev

Abstract. The article examines the lexical and stylistic tools of modern Persian advertising, based on selected 100 slogans. Since the nature of the advertising slogan is multidisciplinary, its emotion depends on the choice and correspondence of lexical and stylistic tools. The study concludes that the language of the modern Persian advertising slogan is expressive. The most commonly used lexical tools in this language are positive for their weight, specific and abstract for their meaning, emotional for their sense, local for their origin, literally for their style, and polysemantic for their definition. Applied stylistic tools may include neologisms, idioms, metaphor, epithet, pun and so forth. Thus, $80 \%$ of expressiveness of slogans used in the study is achieved by lexical tools, whereas $90 \%$ of them is achieved through stylistic tools.

Keywords: lexical, stylistic, modern, advertising, Persian. 